\title{
Scabies mimicking graft versus host disease in a hematopoietic cell transplant recipient
}

\author{
Dongsub Kim, MD', Soo-Han Choi, MD², Dong Youn Lee, MD, PhD, Juyoun Kim, MS ${ }^{4}$, Eunjoo Cho, MS ${ }^{4}$, Keon Hee Yoo, MD, PhD', Hong \\ Hoe Koo, MD, PhD', Yae-Jean Kim, MD, PhD' \\ ${ }^{1}$ Department of Pediatrics, Samsung Medical Center, Sungkyunkwan University School of Medicine, Seoul, ${ }^{2}$ Department of Pediatrics, Hallym University Dongtan \\ Sacred Heart Hospital, Hallym University College of Medicine, Hwasung, ${ }^{3}$ Department of Dermatology, Samsung Medical Center, Sungkyunkwan University School \\ of Medicine, Seoul, ${ }^{4}$ Department of Pediatrics, Samsung Medical Center, Seoul, Korea
}

Scabies is a highly contagious skin infestation caused by the mite, Sarcoptes scabieivar. hominis. Complex responses to scabies mites in the innate, humoral, and cellular immune systems can cause skin inflammation and pruritus. Diagnosis can be challenging because scabies resembles other common skin conditions. We report the first Korean case of scabies in a hematopoietic cell transplant (HCT) recipient, initially suspected of skin graft versus host disease (GVHD). A T-cell acute lymphocytic leukemia patient underwent a sibling-matched allogeneic HCT and developed pruritus after cell engraftment. Treatment for GVHD did not improve the symptoms. He was diagnosed with scabies 30 days after the onset of symptoms.

Key words: Scabies, Graft versus host disease, Hematopoietic cell transplant
Corresponding author: Yae-Jean Kim, MD, PhD Division of Infectious Diseases and Immunodeficiency, Department of Pediatrics, Samsung Medical Center, Sungkyunkwan University School of Medicine, 81 Irwon-ro, Gangnam-gu, Seoul 06351 , Korea

Tel: +82-2-3410-0987

Fax: +82-2-3410-0043

E-mail: yaejeankim@skku.edu

https://orcid.org/0000-0002-8367-3424

Received: 24 October 2018

Revised: 7 November 2018

Accepted: 9 November 2018

\section{Introduction}

Scabies is a contagious skin infestation caused by Sarcoptes scabiei var. hominis. ${ }^{1)}$ The estimated prevalence of human scabies is about 300 million cases yearly in the world. Scabies occurs at all ages and at various socioeconomic levels. ${ }^{2)}$ Epidemics have been liked to poverty, poor water supply, poor sanitation, and overcrowding. Scabies generally causes intense itching sense and secondary bacterial infection can occur. There are also some reports of scabies outbreak in hospitals and nursing homes. ${ }^{3-5)}$

We describe the first Korean case of scabies in an allogeneic hematopoietic cell transplant (HCT) recipient. The patient developed severe pruritus after engraftment, and graft versus host disease (GVHD) was suspected.

The Institutional Review Board (IRB) at Samsung Medical Center, Seoul, South Korea reviewed and approved this study (approval number: 2018-10-112). Informed conset was exempted by IRB.

\section{Case report}

A 13-year-old male patient with T-cell acute lymphocytic leukemia underwent a sibling matched allogeneic HCT in February of 2010. As for conditioning regimen, he received total body irradiation, cytarabine, and cyclophosphamide. Neutrophil engraftment was achieved on posttransplant day 10. His pretransplant varicella zoster virus immunoglobulin (Ig) G was positive and he was on acyclovir prophylaxis and cyclosporine was given for GVHD

Copyright (C) 2018 by The Korean Pediatric Society

This is an open-access article distributed under the terms of the Creative Commons Attribution NonCommercial License (http://creativecommons.org/ licenses/by-nc/4.0/) which permits unrestricted noncommercial use, distribution, and reproduction in any medium, provided the original work is properly cited. 
prophylaxis.

On posttransplant day 12, he developed erythematous papular rash on face and trunk with pruritus. His white blood cell count was 16,670/ $\mu \mathrm{L}$ (neutrophil 75\%, lymphocyte 6\%, eosinophil 0\%). Grade 1 skin graft versus host disease (GVHD) was suspected. Until posttransplant day 21, skin lesions persisted and partial crusted lesions were observed (Fig. 1). He received multiple antihistamine agents and topical steroid but complained of severe itching sensation.

On posttransplant day 28, skin biopsy was performed after a consultation with dermatologists. Skin punch biopsy showed perivascular chronic inflammatory cell infiltration and cytoid body of basal layer (Fig. 2). Conservative treatment for pruritus and management for GVHD was recommended. Systemic corticosteroid, gabapentin, and lorazepam were added.

On posttransplant day 42, a consultation was requested to the pediatric infectious diseases physicians for the evaluation of persistent intense itching sensation and any possible skin infection.

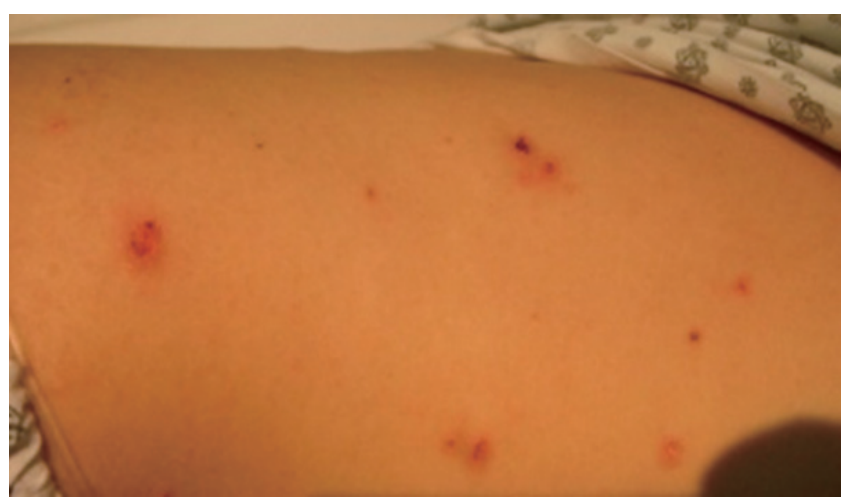

Fig. 1. Erythematous papular rash with partial crusted lesions.

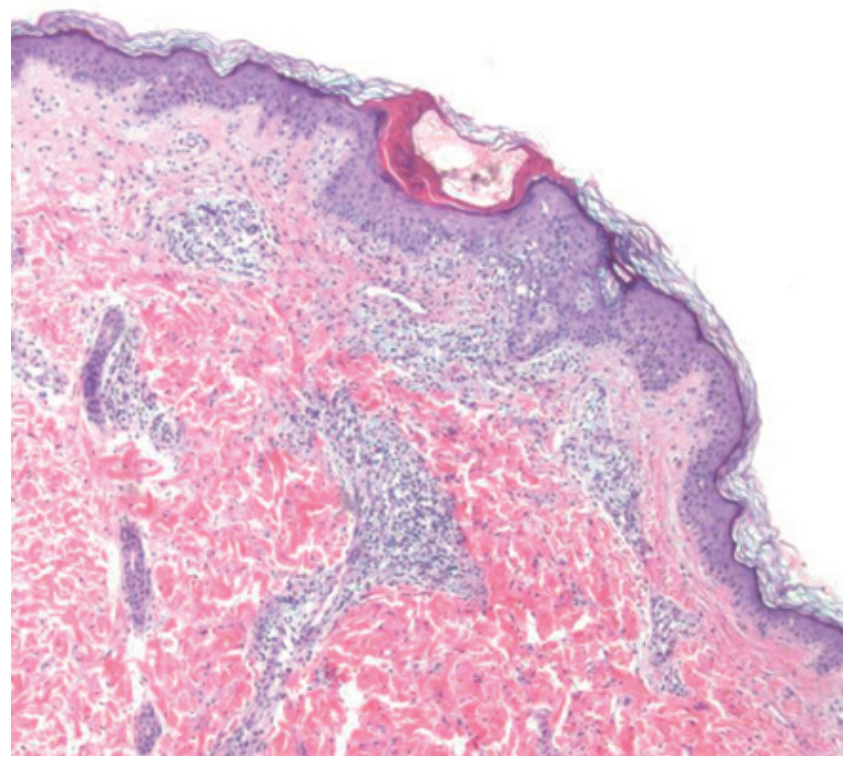

Fig. 2. Perivascular chronic inflammatory cell infiltration and focal liquefaction degeneration of the basal layer with cytoid body $(H \& E, \times 40)$.
When the infectious diseases team visited the patient and questioned, his mother and grandmother reported that they also developed papular rash with itching sensation. An urgent request for an additional evaluation was requested to a dermatologist. A contagious skin infection was suspected and direct smear from his finger web revealed numerous mites (Fig. 3). He was diagnosed with classic scabies and immediately discharged from the hospital because he was otherwise stable except the skin lesions. Crotamiton ointment was applied for treatment at home. Currently, crotamiton is not recommended by U.S. Food and Drug Administration with safety concerns.

After a week, pruritus subsided and skin lesions continued to improve during the 6 weeks of outpatient clinic follow-up visits.

An investigation was performed in all potentially exposed individuals in the hospital. Infection control intervention and environmental disinfection were also performed to prevent the institutional outbreak. There were no other scabies cases from this nosocomial exposure.

\section{Discussion}

This is the first Korean case of scabies in a 13-year-old acute leukemia patient who underwent HCT. The patient developed symptoms after the engraftment of hematopoietic stem cells and acute GVHD was mostly suspected. Scabies was diagnosed with additional history taking of family members after 30 days of symptom onset.

With improved sanitation, clinicians are unfamiliar with scabies. Scabies can be misdiagnosed as seborrheic dermatitis, eczematous dermatitis, impetigo, arthropod bites, and Langerhans cell histiocytosis. ${ }^{6}$ In our case, patient's clinical situation involving allogeneic HCT made us suspect GVHD with high priority. The number of HCT is increasing and there are various situations during the posttransplant period. Therefore, unusual infectious pathogens should be considered in patients with atypical skin conditions.

There are many studies about pathogenesis of scabies explaining complex innate, humoral, and cellular responses in human. Pre-

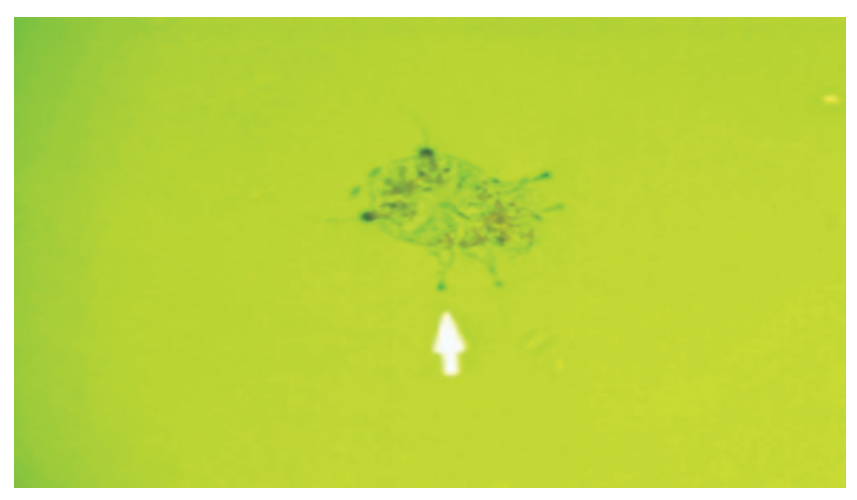

Fig. 3. Direct smear from hand web spaces revealing mites (white arrow). 
Table 1. Reports of scabies infestation in stem cell transplant recipient

\begin{tabular}{|c|c|c|c|c|c|c|c|}
\hline Study & $\begin{array}{l}\text { Age/ } \\
\text { sex }\end{array}$ & $\begin{array}{l}\text { Underlying } \\
\text { condition }\end{array}$ & HCT type & $\begin{array}{c}\text { Sx } \\
\text { onset* }^{*}\end{array}$ & Skin condition & Skin biopsy & Day of diagnosis* \\
\hline Barnes et al. ${ }^{11)}(1987)$ & $4 / \mathrm{M}$ & ALL & Allogeneic & $D-13$ & Crusted papules on hands and feet & $\mathrm{N} / \mathrm{A}$ & $D+23$ \\
\hline Vyas et al. ${ }^{12)}(1990)$ & $23 / F$ & ALL & Autologous & $\mathrm{D}+18$ & Crusted hyperkeratotic burrow & $\mathrm{N} / \mathrm{A}$ & $D+38$ \\
\hline Cheng et al. ${ }^{13)}$ (2001) & $12 / M$ & Dyskeratosis congenita & Allogeneic & $D+4$ & Erythematous nodules on scrotum & Yes (skin GVHD) & $\mathrm{N} / \mathrm{A}$ (skin biopsy on $\mathrm{D}+17$ ) \\
\hline $\begin{array}{l}\text { Ortega-Loayza et al. }{ }^{14)} \\
(2013)\end{array}$ & $61 / M$ & AML & Allogeneic & $D+28$ & Erythematous papules and excoriations & N/A & N/A \\
\hline Present study & $13 / \mathrm{M}$ & ALL & Allogeneic & $\mathrm{D}+12$ & Erythematous papules with partial crust & Yes (skin GVHD) & $D+42$ \\
\hline
\end{tabular}

HCT, hematopoietic cell transplant; Sx, symptom; GVHD, graft versus host disease; ALL, acute lymphoblastic leukemia; AML, acute myeloid leukemia; N/A, not available.

${ }^{*} \mathrm{D} 0$, transplant day.

dominant CD8+ T cell infiltration and absence of B cells were demonstrated in skin lesions of crusted scabies indicating cellular immunity contribute to the inflammation. ${ }^{8)}$ Skin rash and itching sensation with scabies are associated with type I (immediate) and type IV (delayed) hypersensitivity.9) In a prospective Australian study, serum IgE level was markedly elevated in 96\% of scabies patients. ${ }^{10)}$ There are little data on immune response in a HCT setting. In our patient, he developed symptoms after the engraftment which represents beginning of immune recovery and also a usual period of acute GVHD development.

Previous reports of scabies among HCT recipients who developed symptoms within 100 days are described (Table 1). There were three pediatric patients including one in this report. All the pediatric patients underwent allogeneic HCT. Two children underwent skin biopsy and were initially diagnosed with skin GVHD. In all pediatric cases, it took more than 2 weeks to diagnose scabies.

In conclusion, although not common, clinicians should consider scabies as a possible condition in patients with unusual intense pruritus and additional itching persons in close contacts even in HCT recipients.

\section{Conflict of interest}

No potential conflict of interest relevant to this article was reported.

\section{References}

1. Romani L, Whitfeld MJ, Koroivueta J, Kama M, Wand H, Tikoduadua
L, et al. Mass drug administration for scabies control in a population with endemic disease. N Engl J Med 2015;373:2305-13.

2. Chosidow 0. Clinical practices. Scabies. N Engl J Med 2006;354:171827.

3. Park H, Lee C, Park S, Kwon H, Kweon SS. Scabies among elderly Korean patients with histories of leprosy. Am J Trop Med Hyg 2016; 95:75-6.

4. Ahn YS, Lim HS. Occupational infectious diseases among Korean health care workers compensated with Industrial Accident Compensation Insurance from 1998 to 2004. Ind Health 2008;46:448-54.

5. Smith DR, Choi JW, Yu DS, Ki M, Oh CH, Yamagata Z. Skin disease among staff in a large Korean nursing home. Tohoku J Exp Med 2002;198:175-80.

6. Peterson CM, Eichenfield LF. Scabies. Pediatr Ann 1996;25:97-100.

7. Wang CX, Anadkat MJ, Musiek AC. Dermatologic conditions of the early post-transplant period in hematopoietic stem cell transplant recipients. Am J Clin Dermatol 2018 0ct 8 [Epub]. https://doi. org/10.1007/s40257-018-0391-4.

8. Walton SF, Beroukas D, Roberts-Thomson P, Currie BJ. New insights into disease pathogenesis in crusted (Norwegian) scabies: the skin immune response in crusted scabies. Br J Dermatol 2008;158:124755.

9. Bhat SA, Mounsey KE, Liu X, Walton SF. Host immune responses to the itch mite, Sarcoptes scabiei, in humans. Parasit Vectors 2017; 10:385.

10. Roberts LJ, Huffam SE, Walton SF, Currie BJ. Crusted scabies: clinical and immunological findings in seventy-eight patients and a review of the literature. J Infect 2005;50:375-81.

11. Barnes L, McCallister RE, Lucky AW. Crusted (Norwegian) scabies. Occurrence in a child undergoing a bone marrow transplant. Arch Dermatol 1987;123:95-7.

12. Vyas P, Kinsey SE, Goldstone AH. Scabies infestation following autologous bone marrow transplantation. Leuk Lymphoma 1990;3:73-4.

13. Cheng VC, Yuen KY, Wong SS, Woo PC, Ho PL, Lee R, et al. Immunorestitution diseases in patients not infected with HIV. Eur J Clin Microbiol Infect Dis 2001;20:402-6.

14. Ortega-Loayza AG, McCall CO, Nunley JR. Crusted scabies and multiple dosages of ivermectin. J Drugs Dermatol 2013;12:584-5. 